\title{
TEM Phase Transitions Analysis in Human Tooth Enamel
}

José Reyes-Gasga $^{1 *}$ and Nancy Vargas-Becerril ${ }^{1}$

${ }^{1}$ Instituto de Física, UNAM, Circuito de la Investigación s/n, Ciudad Universitaria. 04510 Coyoacán, Ciudad de México, México.

* Corresponding author: jreyes@física.unam.mx

As the dental piece heats up, morphological and chemical changes are evidenced by changes in color and fractures, as well as changes in hardness and electrical conductivity [1]. The understanding of these changes can be useful in the design of new materials and implants for dental use, among others.

The human tooth is a composite material made up of enamel and dentin. Enamel is a prismatic structure containing $96 \%$ by weight of nanometric crystals of hydroxyapatite (HAP, Ca10(PO4)6 (OH)2), and $4 \%$ of organic material and water (Le Geros 1991; Shahmoradi et al., 2014). Dentin is a tubular structure that connects the pulp with the amelodentinal junction. Dentin tubules are surrounded by HAP crystals that constitute 70\% by weight and the remaining 30\% consists of organic material and water (Le Geros 1991; Shahmoradi et al., 2014).

In this work we present the scanning electron microscopy (SEM) and transmission electron microscopy TEM heating behavior of human tooth enamel. Structural changes in teeth with temperature are evidenced by color changes and fractures [1]. Researchers have analyzed the heating behavior of teeth, but none have done this by TEM. Sandholzer et al. [2] suggested that temperature produces a perfection in the crystal structure of teeth. Fereira et al. [3] indicated that dentin and enamel are abruptly separated at the enameldentin junction and fracture damage is severe when heating is fast. In addition, there has been indication that $\mathrm{CO}_{2}$ lasers raise the temperature up to $800{ }^{\circ} \mathrm{C}$ at the application site [4].

In this work, bulk samples of human tooth enamel from molar teeth were calcined in air from room temperature $\left(25^{\circ} \mathrm{C}\right)$ up to $1200{ }^{\circ} \mathrm{C}$ to study the structural changes by transmission electron microscopy (TEM), and the coexistence of HAP and $\beta$ tricalcium phosphate ( $\beta$-TCP) was observed.

Figure 1 shows TEM images of enamel at different temperatures. At $200{ }^{\circ} \mathrm{C}$ the elongated HAP crystals coalesce occurs, and above $600{ }^{\circ} \mathrm{C}$ a molten structure, initially porous $\left(1000{ }^{\circ} \mathrm{C}\right)$ and continuous after $\left(1200{ }^{\circ} \mathrm{C}\right)$, is observed. At $1200{ }^{\circ} \mathrm{C}$, the percentage of HAP is $91 \%$ HAP and $8 \%$ of $\beta$-TCP. Electron diffraction analysis have indicated the HAP structure in most of the crystals. This is so because the similarity between the diffraction patterns in the direction [12 $\overline{13}$ ] of HAP with that in the direction [112 $\overline{0}]$ of the $\beta$-TCP phase. The results indicated a high correlation relationship among $\mathrm{Ca}, \mathrm{P}, \mathrm{O}$ and $\mathrm{Na}$, and the existence of the Kirkendall effect during the HAP- $\beta$-TCP phase transition.

References:

[1]. N. Vargas-Becerril et al., Mater. Sci. Appl. 9 (2018) 637-656.

[2]. M.A. Sandholzer et al., J Forensic Sci 59 (2014) 769-774.

[3]. J.L. Fereira et al., Forensic Sci Int 178 (2008) 119-124.

[4]. B.S. Yilbas et al., Opt Laser Technol 28 (1996) 513-519.

[5]. We thank J. Barreto, S. Tehuacanero-Nuñez, R. Trejo, A. Gómez, A. Morales, M. Aguilar, D. Quiterio, C. Zorrilla, and S. Tehuacanero-Cuapa from IFUNAM for technical support, and E. Saucedo and E. Díaz Barriga from CIQA for sample preparation. We also thank to DGAPA-UNAM for the financial support (project PAPIIT No. IN-101319). 

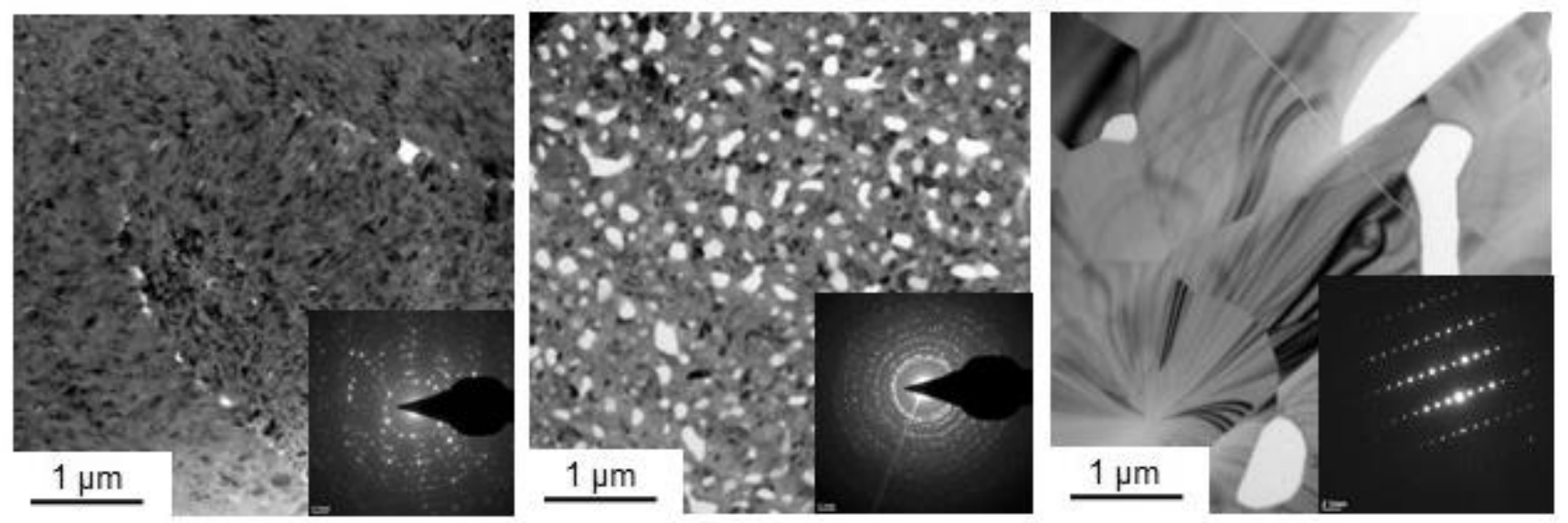

Figure 1. TEM images of the structure changes observed in enamel at different temperatures. 